\title{
Поиск возможных каталитических систем для синтеза сверхсшитых полистирольных сорбентов
}

\author{
Цюрупа М.П., Блинникова 3.К., Давидович Ю.А., Даванков В.А. \\ ФГБУН Институт элементоорганических соединений им. А.Н. Несмеянова РАН, Москва \\ Поступила в редакцию 18.04.2019 г.
}

DOI: https://doi.org/10.17308/sorpchrom.2019.19/776

С целью упрощения и удешевления синтеза сверхсшитых сорбентов вновь изучена реакция сшивания набухшего в дихлорэтане сополимера стирола с $0.7 \%$ ДВБ монохлордиметиловым эфиром по реакции Фриделя-Крафтса. Пористые полимеры с удельной поверхностью 800-1000 м²/Г можно получить, используя 1 моль дорогих безводных $\mathrm{SnCl}_{4}$ и $\mathrm{TiCl}_{4}$ на моль эфира. Безводные $\mathrm{AlCl}_{3}$ и $\mathrm{FeCl}_{3}$ вызывают деструкцию исходного сополимера, а $\mathrm{ZnCl}_{2}$ оказался неактивным. Однако раствор смеси 70 г $\mathrm{ZnCl}_{2}$ и 3.5 г $\mathrm{FeCl}_{3}$ в $50 \mathrm{~cm}^{3}$ концентрированной соляной кислоты является перспективным катализатором. Выполняя одновременно роль многоразового катализатора и дисперсионной среды, он позволил впервые получить пористые гранулы даже из линейного полистирола, проводить сшивание полимера без его деструкции и заменить эфир нетоксичным метилалем.

Ключевые слова: сверхсшитые сорбенты, полистирол, катализаторы Фриделя-Крафтса

\section{Search for perspective catalytic systems for synthesis of hypercrosslinked polystyrene sorbents}

\author{
Tsyurupa M.P., Blinnikova Z.K., Davidovich Yu.A., Davankov V.A.
}

Nesmeyanov-Institute of Organoelement Compounds RAS, Moscow

This study was focused on resolving an important technical task, namely, designing of a convenient method for preparing hypercrosslinked polystyrene sorbents. The developed method should be simple, onestep, reasonably priced and suitable for scaling up. It also should allow obtaining beaded polymers starting both from linear polystyrene and styrene-DVB copolymers. As a part of the formulated task, the bridging of dichloroethane-swollen styrene-0.7\% DVB copolymer with monochlorodimethyl ether via Friedel-Crafts reaction has been re-examined. Experiments conducted with anhydrous catalysts $\left(\mathrm{AlCl}_{3}, \mathrm{FeCl}_{3}, \mathrm{SnCl}_{4}, \mathrm{TiCl}_{4}\right.$ and $\mathrm{ZnCl}_{2}$ ) showed that basically it is possible to prepare hypercrosslinked sorbents with apparent inner surface area of 800 to $1000 \mathrm{~m}^{2} / \mathrm{g}$ provided one takes one mole of the catalyst per mole of the ether. However, $\mathrm{AlCl}_{3}$ and $\mathrm{FeCl}_{3}$ cause degradation of the initial copolymer. The reaction proceeded too slow in the presence of $\mathrm{TiCl}_{4}$ while $\mathrm{ZnCl}_{2}$ proved to be inactive. Sill, tin tetrachloride is the most convenient catalyst for scientific researches. Unexpectedly, it was found out that $\mathrm{FeCl}_{3} \cdot 6 \mathrm{H}_{2} \mathrm{O}$ is capable of catalyzing the reaction of MCDE with polystyrene, though the inner surface area of resulting polymers did not exceed $170 \mathrm{~m}^{2} / \mathrm{g}$. This finding suggested to examine aqueous acidic solutions of Lewes acids as catalysts. Of all the catalysts tested only $\mathrm{AlCl}_{3}$ lost its activity in the presence of water because of complete hydrolysis till alumina, while $\mathrm{FeCl}_{3}$, $\mathrm{SnCl}_{4}$ and $\mathrm{ZnCl}_{2}$ more or less maintain their catalytic capability. The best results were obtained when using a solution of $70 \mathrm{~g} \mathrm{ZnCl}_{2}$ and $3.5 \mathrm{~g} \mathrm{FeCl}_{3}$ in $50 \mathrm{~mL}$ of concentrated hydrochloric acid. Being simultaneously a catalytic system and a dispersion medium, this solution within 7-10 hours allows introducing $100 \%$ bridges in styrene- $0.7 \%$ DVB copolymer and obtaining a porous material with inner surface area as high as $1000 \mathrm{~m}^{2} / \mathrm{g}$. The volume ratio of inorganic and organic phases may be varied from 3.5:1 to 0.4:1 every time obtaining polymers with the same surface area. Importantly, instead of beaded styrene-DVB copolymers one 
can use a solution of linear polystyrene and, in addition, replace the ether with methylal, thus preparing beaded material with inner surface area of $800-1000 \mathrm{~m}^{2} / \mathrm{g}$. This procedure opens a way to the utilization of waste polystyrene packing material and its transformation into useful porous sorbents.

Keywords: hypercrosslinked sorbents, polystyrene, Friedel-Crafts catalysts

\section{Введение}

Сверхсшитые полистирольные сорбенты снискали заслуженную популярность во всем мире благодаря их удивительной способности эффективно и обратимо поглощать как гидрофобные, так и гидрофильные органические вещества. Это свойство обусловливает использование сверхсшитых сорбентов в различных областях деятельности человека: в промышленном масштабе от осветления сахарных сиропов и цитрусовых соков [1] до получения чистейшего хлористого водорода [2], а в аналитической химии - для пре-концентрирования загрязнителей воды и воздуха с целью их последующей идентификации и количественного определения современными аналитическими методами[1].

Принцип синтеза сверхсшитого полистирола заключается в интенсивном сшивании цепей полистирола в растворе или в набухшем геле бифункциональными (полифункциональными) реагентами, образующими в сетке конформационно жесткие мостики. В качестве сшивающего агента в своих работах мы чаще всего использовали монохлордиметиловый эфир (МХДЭ). Он количественно реагирует с полистиролом в присутствии катализатора Фриделя-Крафтса $\left(\mathrm{SnCl}_{4}\right)$, связывая два фенильных кольца полимерных цепей метиленовой группой. Помимо высокой реакционной способности, эфир обладает тем важным для характеристики сеток свойством, что он не образует продуктов самоконденсации. Поэтому мы использовали эфир для синтеза и исследования свойств сверхсшитых сорбентов полученных как на основе линейного полистирола (ПС), так и путем дополнительного структурирования набухших гранул сополимеров стирола с дивинилбензолом (ДВБ). Однако в США и в странах Европы запрещено использовать эфир в промышленном масштабе, так как принято считать, что технический продукт МХДЭ содержит примесь канцерогенного бис-хлорметилового эфира. Чтобы избежать прямого использования эфира, многие химические фирмы производят сверхсшитые сорбенты в две стадии: сначала в сополимеры стирола с ДВБ вводят $\mathrm{ClCH}_{2}$ группы тем или иным известным им безопасным методом, выделяют полученный продукт, а затем проводят реакцию алкилирования фенильных колец полистирольных цепей хлорметильными группами в присутствии, как правило, небольших количеств хлорного железа [3-5]. Не вызывает сомнения, что двухстадийный способ синтеза сорбентов дороже, чем синтезы, проводимые в одну стадию.

Сшивание сополимеров стирола с ДВБ позволяет получать сверхсшитый сорбент в форме сферических гранул, столь необходимых для результативной работы адсорбционных колонн в динамических условиях. Напротив, структурирование раствора ПС приводит к образованию единого блока набухшего геля, который необходимо дробить. Поэтому частицы конечного продукта имеют неправильную форму. Однако сверхсшитые сетки на основе линейного полистирола обладают большей набухаемостью и лучшей проницаемостью, особенно, для крупных органических молекул. В связи с этим, задача придания сферической формы частицам сверхсшитых сорбентов на основе линейного ПС и по сей день является актуальной задачей.

В связи с вышесказанным мы поставили перед собой задачу разработать простой одностадийный, достаточно дешевый и легко масштабируемый способ синтеза сверхсшитых сорбентов в виде сферических гранул, как исходя из сополимеров стирола с ДВБ, так и на основе растворов линейного ПС. В рамках поставленной задачи 
необходимо было в первую очередь оценить пригодность наиболее распространенных безводных катализаторов Фриделя-Крафтса, а также возможность использования водных растворов кислот Льюиса для синтеза сверхсшитых высокопористых полистиролов. Полученные результаты представлены в данной работе.

\section{Эксперимент}

Материалы и реактивы. Все кислоты Льюиса, $\mathrm{NaCl}$, параформ, метанол, метилаль, толуол, серная и соляная кислоты, стирол, 55\% дивинилбензол, 1,2дихлорэтан (все производства России) были использованы без дополнительной очистки. Линейный полистирол с молекулярной массой 300000 был также промышленного производства России.

Синтезы сшитых полимеров и МХДЭ.

Синтез монохлордиметилового эфира. В 4-х горлую колбу, снабженную мешалкой, капельной воронкой, термометром и обратным холодильником, вносили 32 мл (1 моль) метилового спирта и 30 г (1 моль) предварительно растертого порошкообразного параформа. Смесь тщательно перемешивали и добавляли 30 г тонко измельченного $\mathrm{NaCl}$. Реакционную массу охладили до $-5^{\circ} \mathrm{C}$ и при этой температуре медленно в течение 1 часа добавляли по каплям 120 мл концентрированной соляной кислоты. Затем также медленно при $-5^{\circ} \mathrm{C}$ и перемешивании прикапывали 120 мл концентрированной серной кислоты. Перемешивание и охлаждение продолжали еще 5 часов до полного растворения параформа. После завершения реакции верхний слой отделяли и перегоняли, отбирая фракцию с температурой кипения 59-61 ${ }^{\circ} \mathrm{C}$ (по литературным данным [6] температура кипения эфира $\left.58.5^{\circ} \mathrm{C}\right)$. Выход эфира $60 \%$.

Синтез гелевого сополимера стирола с $0.7 \%$ ДВБ путем радикальной полимеризации сомономеров проводили традиционным суспензионным методом, используя в качестве инициатора перекись бензоила и поливиниловый спирт в качестве стабилизатора суспензии. Соотношение органической и водной фаз было 1:3. Реакцию проводили 8 часов при $80^{\circ} \mathrm{C}$. Полученный сополимер промывали горячей водой, этиловым спиртом и дистиллированной водой. Полимер сушили при $100^{\circ} \mathrm{C}$.

Синтез сверхсшитых сорбентов в двухфазной водной системе проводили, суспендируя 10\% раствор ПС и сшивателя (МХДЭ или метилаля) в 1,2-дихлорэтане или полностью набухшие в смеси дихлорэтана и сшивающего агента гранулы сополимера стирола с $0.7 \%$ ДВБ (свободные от избыточной межгранульной жидкости) в кислом водном растворе катализаторов Фриделя-Крафтса. Реакцию вели 7-10 часов при $70-80^{\circ} \mathrm{C}$, после чего полученный продукт отфильтровывали, промывали ацетоном, разбавлено соляной кислотой, водой и высушивали при $100^{\circ} \mathrm{C}$.

Для синтеза сверхсшитых полимеров в безводных условиях гранулы сополимера стирола с $0.7 \%$ ДВБ, набухшие в небольшом избытке дихлорэтана и МХДЭ, охлаждали до $5^{\circ} \mathrm{C}$, добавляли катализатор и через 15 мин температуру постепенно повышали до $80^{\circ} \mathrm{C}$. При этой температуре реакцию вели не менее 10 час при постоянном перемешивании. Полученный продукт отфильтровывали и промывали как описано выше.

Характеристика полученных сорбентов.

Набухаемость полимеров в толуоле определяли весовым методом как количество растворителя, поглощенное 1 граммом сухого полимера, удаляя избыток растворителя центрифугированием в течение 15 мин при 4000 об/мин.

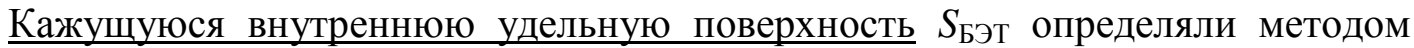
тепловой десорбции аргона на приборе «Цвет 211» и рассчитывали по теории БЭТ.

Цюрупа и др. / Сорбционные и хроматографические процессы. 2019. Т. 19. № 4 


\section{Обсуждение результатов}

В попытках упростить и удешевить синтез сверхсшитых полимеров прежде всего была модифицирована методика синтеза монохлордиметилового эфира. Из всех использованных в наших исследованиях сшивающих агентов [1] МХДЭ является наиболее удобным реагентом. Однако его традиционный синтез, основанный на пропускании газообразного хлористого водорода через смесь параформа и метанола, приводит к получению смеси соединений, содержащей как высококипящие примеси, так и непрореагировавший параформ. Последний возгоняется при перегонке сырого продукта, что сильно осложняет получение чистого эфира. Мы модифицировали известную методику синтеза МХДЭ, используя смесь концентрированных соляной и серной кислот и $\mathrm{NaCl}$ как in situ источник $\mathrm{HCl}$. Это позволило нам получить чистый продукт, кипящий в очень узком интервале температур $\left(58-60^{\circ} \mathrm{C}\right)$ и не содержащий свободного параформа. По данным газохроматографического анализа в перегнанном эфире нет соединений с температурой кипения выше $60^{\circ} \mathrm{C}$ (напомним, что канцерогенный бис-хлорметиловый эфир кипит при $105^{\circ} \mathrm{C}$ [7]). Всё же при работе с эфиром надо все же иметь в виду, что МХДЭ относится к соединениям 3 класса опасности CAS 107-30-2 и вызывает раздражение дыхательных путей [8].

На следующем этапе исследований с целью замены дорогостоящего хлорного олова был проведен скрининг наиболее распространенных катализаторов реакции Фриделя-Крафтса. Возможность их использования мы изучали, сшивая предельно набухший в дихлорэтане сополимер стирола с $0.7 \%$ ДВБ 0.5 молями МХДЭ, что соответствует $100 \%$ степени сшивки конечного продута. В качестве критерия пригодности катализатора для синтеза сверхсшитого полимера была выбрана величина его кажущейся внутренней удельной поверхности, которая при использовании хлорного олова составляла в среднем $1000 \mathrm{~m}^{2} / г$. В таблице 1 приведены опробованные катализаторы. Они расположены в порядке уменьшения их активности в реакции алкилирования ароматических соединений галоидалкилами.

Таблицы 1. Сшивание сополимера стирола с $0.7 \%$ ДВБ монохлордиметиловым эфиром при $80^{\circ} \mathrm{C}$ в присутствии безводных катализаторов Фриделя-Крафтса.

\begin{tabular}{|c|c|c|c|c|c|}
\hline \multicolumn{2}{|c|}{ Катализатор } & \multirow{2}{*}{$\begin{array}{c}\text { МХДЭ } \\
\text { моль/моль } \\
\text { ПС }\end{array}$} & \multirow{2}{*}{$\begin{array}{l}\text { Время, } \\
\text { час }\end{array}$} & \multirow{2}{*}{$\begin{array}{c}\text { Набухание } \\
\text { в толуоле, } \\
\text { г/г }\end{array}$} & \multirow{2}{*}{$\begin{array}{l}\mathrm{S}_{\mathrm{yд}}, \\
\mathrm{M}^{2} / \Gamma\end{array}$} \\
\hline Тип & $\begin{array}{c}\text { моль/моль } \\
\text { МХДЭ }\end{array}$ & & & & \\
\hline \multirow{3}{*}{$\mathrm{AlCl}_{3}$} & 0.5 & 0.5 & 10 & 1.44 & 0 \\
\hline & 0.8 & 0.5 & 10 & 1.46 & 315 \\
\hline & 1.0 & 0.5 & 10 & 1.43 & 980 \\
\hline \multirow{2}{*}{$\mathrm{FeCl}_{3}$} & 0.5 & 0.5 & 10 & 2.46 & 670 \\
\hline & 1.0 & 0.5 & 10 & 2.42 & 1300 \\
\hline \multirow{2}{*}{$\mathrm{SnCl}_{4}{ }^{*}$} & 1.0 & 1.0 & 10 & 1.32 & 1750 \\
\hline & 0.1 & 1.0 & 10 & 1.0 & 0 \\
\hline \multirow{3}{*}{$\mathrm{TiCl}_{4}$} & 0.5 & 0.5 & 20 & 1.25 & 7 \\
\hline & 0.7 & 0.5 & 20 & 1.37 & 230 \\
\hline & 1.0 & 0.5 & 20 & 1.40 & 840 \\
\hline \multirow{2}{*}{$\mathrm{ZnCl}_{2}$} & 0.5 & 0.5 . & 10 & 1.15 & 0 \\
\hline & 1.0 & 0.5 & 10 & 1.10 & 0 \\
\hline \multirow{4}{*}{$\mathrm{FeCl}_{3} 6 \mathrm{H}_{2} \mathrm{O}$} & 0.5 & 0.5 & 10 & 1.08 & 10 \\
\hline & 0.8 & 0.5 & 10 & 1.03 & 55 \\
\hline & 1.0 & 0.5 & 10 & 1.05 & 65 \\
\hline & 0.8 & 0.5 & 35 & 0.82 & 167 \\
\hline
\end{tabular}

\footnotetext{
* в эксперименте использован сополимер стирола с $0.5 \%$ ДВБ
} 
Как следует из таблицы 1 , за разумное время нагревания реакционной массы (10 часов при $80^{\circ} \mathrm{C}$ ) получить высокопористые полимеры можно только при использовании 1 моля $\mathrm{AlCl}_{3}, \mathrm{FeCl}_{3}, \mathrm{SnCl}_{4}$ или $\mathrm{TiCl}_{4}$ на моль сшивающего агента. При этом самые перспективные катализаторы, хлористый алюминий и хлорное железо, оказались непригодными для решения поставленной задачи, поскольку они вызывают практически полную деструкцию гранул слабо сшитого сополимера. Определить величину поверхности продуктов, полученных с этими катализаторами, удалось, выделив лишь небольшое число целых гранул из общей кашеобразной массы. К тому же весьма вероятно, что оба катализатора способствуют реакции дихлорэтана с исходным сополимером. $\mathrm{SnCl}_{4}$ - активный катализатор, он растворим во многих органических растворителях, его удобно дозировать, но, как уже упоминалось, он является дорогим реагентом. $\mathrm{TiCl}_{4}$ не разрушает гранулы, но и он позволяет получать сверхсшитые сетки с поверхностью $840 \mathrm{~m}^{2} / \Gamma$ при мольном соотношении $\mathrm{TiCl}_{4}: \mathrm{MXДЭ}$ $1: 1$ и времени реакции 20 часов. Наконец, $\mathrm{ZnCl}_{2}$ в стандартных условиях реакции $\left(80^{\circ} \mathrm{C}, 10\right.$ часов) не позволяет получить пористый материал. Тем не менее, он катализирует реакцию МХДЭ с полистиролом, так как набухание полученных полимеров в толуоле составляет 1.15 г/г, что в несколько раз ниже набухания в этом растворителе исходного сополимера, 4.5 г/г.

Стоит отметить, что набухание в толуоле всех синтезированных полимеров

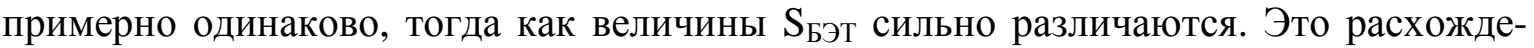
ние связано с тем, что увеличение степени дополнительного сшивания сополимера выше $25 \%$ уже не сказывается на набухании полученных продуктов, а истинная пористость, как известно, появляется лишь при степени сшивки выше 40\% [1]. Скорее всего, в мягких условиях реакции эта желаемая степень сшивки не достигается.

Весьма интересно, что кристаллогидрат хлорного железа $\mathrm{FeCl}_{3} 6 \mathrm{H}_{2} \mathrm{O}$ также катализирует реакцию эфира с сополимером: за 10 часов нагревания можно получить полимеры с удельной поверхностью $10-65 \mathrm{~m}^{2} / \Gamma$, а за 35 часов реакции поверхность возрастает до $167 \mathrm{~m}^{2} / \Gamma$. (таблица 1) Полученные результаты наводят на мысль, что значительное количество воды, присутствующее в катализаторе, не является непреодолимым препятствием для синтеза высокопористых сверхсшитых полимеров. В результате мы пришли к парадоксальному решению использовать в качестве каталитической системы водные растворы катализаторов Фриделя-Крафтса. Для предотвращения гидролиза каталитически активных солей, они были растворены в концентрированной соляной кислоте.

Принцип синтеза сшитых полимеров в присутствии водных растворов катализаторов Фриделя-Крафтса состоит в следующем. Раствор линейного полистирола и сшивающего агента в несмешивающимся с водой растворителе (дихлорэтане, тетрахлорэтане или нитробензоле) диспергируют в растворе катализатора, который одновременно выполняет роль дисперсионной среды. Катализатор диффундирует из водной фазы в органическую, где и происходит реакция. Полученный продукт имеет форму сферических гранул. Понятно, что в качестве исходного полимера можно также использовать набухшие в растворителе и сшивателе гранулы сополимера стирола с ДВБ.

Из всех испытанных катализаторов $\left(\mathrm{AlCl}_{3}, \mathrm{FeCl}_{3}, \mathrm{SnCl}_{4}, \mathrm{ZnCl}_{2}\right)$ только хлористый алюминий полностью теряет свою активность в солянокислой среде из-за его гидролиза с образованием нерастворимой в кислотах и щелочах окиси алюминия. Исследования, проведенные на качественном уровне с раствором линейного ПС, показали, что $\mathrm{FeCl}_{3}$ и $\mathrm{SnCl}_{4}$ при их большой концентрации в соляной кислоте (вплоть до 100 г в $50 \mathrm{~cm}^{3}$ ) сохраняют достаточно высокую активность и приводят к получению сшитых полимеров за относительно небольшой промежуток времени. Хлори- 
стый цинк катализирует сшивание ПС МХДЭ только в среде нитробензола. Напротив, концентрированный раствор $\mathrm{FeCl}_{3}$ в соляной кислоте высаживает полистирол из раствора в нитробензоле, но катализирует реакцию в дихлорэтане. В качестве сшивающих агентов можно использовать не только МХДЭ, но также и бисхлорметильные производные бензола и дифенила.

Наиболее приемлемым катализатором для синтеза сверхсшитых пористых полимеров оказалась смесь $\mathrm{ZnCl}_{2}$ и $\mathrm{FtCl}_{3}$ в концентрированной $\mathrm{HCl}$. Интересно отметить, что раствор хлористого цинка сам по себе не катализирует сшивание полистирола в дихлорэтане, но добавка примерно $5 \% \mathrm{FeCl}_{3}$ делает эту смесь весьма активной. Для проведения количественных экспериментов мы использовали смешанный катализатор, в котором весовое соотношение компонентов составляло 70 г $\mathrm{ZnCl}_{2}$ и 3.5 г $\mathrm{FeCl}_{3}$ в $50 \mathrm{~cm}^{3}$ кислоты. В мольном выражении оно соответствует: 1.0 моль $\mathrm{ZnCl}_{2}$ и 0,04 моля $\mathrm{FeCl}_{3}, 4.1$ моля $\mathrm{H}_{2} \mathrm{O}$ и 1.1 моля $\mathrm{HCl}$. Вместо безводного хлорного железа проще использовать примерно такое же количество $\mathrm{FeCl}_{3}: 6 \mathrm{H}_{2} \mathrm{O}$.

В таблице 2 даны условия дополнительного сшивания набухшего в дихлорэтане сополимера стирола с $0.7 \%$ ДВБ монохлордиметиловым эфиром в указанной диспергирующей среде. Из этих данных следует, что используя соотношение неорганической и органической фаз 3.5:1 и 0.6-1.0 моль МХДЭ на основомоль полистирола за 7 часов можно получить высокопористые сверхсшитые полимеры с удельной поверхностью 870-1200 м²/г. При этом все полимеры поглощают примерно одинаковое количество толуола, 0.84-0.90 г/г. Примечательно, что объем каталитической смеси можно уменьшить до соотношения фаз 1:1 и даже до 0.4:1, если в реакцию вводить 1.0 моль эфира. Однако при этом набухание сшитых полимеров в толуоле уменьшается до 0.50-0.65 г/г.

Таблица 2. Сшивание набухшего в дихлорэтане сополимера стирола с $0.7 \%$ ДВБ МХДЭ в присутствии раствора $\mathrm{ZnCl}_{2}$ и $\mathrm{FeCl}_{3}$ в соляной кислоте (объем полимерной фазы $23 \mathrm{~cm}^{3}, 80^{\circ} \mathrm{C}$ )

\begin{tabular}{|c|c|c|c|c|}
\hline $\begin{array}{c}\text { Количество } \\
\text { МХДЭ, моль }\end{array}$ & $\begin{array}{c}\text { Объем катализа- } \\
\text { тора, } \mathrm{cm}^{3}\end{array}$ & $\begin{array}{c}\text { Время реакции, } \\
\text { час }\end{array}$ & $\begin{array}{c}\text { Набухание в то- } \\
\text { луоле, г/Г }\end{array}$ & $\mathrm{S}_{\text {уд }, \mathrm{M}^{2} / \Gamma}$ \\
\hline 0.5 & 80 & 5 & 0.93 & 80 \\
\hline 0.5 & 80 & 7 & 0.56 & 370 \\
\hline 0.5 & 80 & 10 & 0.83 & 370 \\
\hline 0.6 & 80 & 7 & 0.84 & 1200 \\
\hline 0.7 & 80 & 7 & 0.89 & 870 \\
\hline 0.8 & 80 & 7 & 0.90 & 1000 \\
\hline 1.0 & 80 & 7 & 0.90 & 1000 \\
\hline 1.0 & 40 & 7 & 0.65 & 1100 \\
\hline 1.0 & 25 & 7 & 0.60 & 870 \\
\hline 1.0 & 10 & 7 & 0.55 & 810 \\
\hline
\end{tabular}

Структурирование линейного полистирола, растворенного в дихлорэтане, метилалем приводит к получению полимеров с приемлемыми величинами $\mathrm{S}_{\text {Бэт }} 800$ $1000 \mathrm{~m}^{2} / \Gamma$ только при большом количестве сшивающего агента (таблица 3). Тем не менее, из данных таблицы 3 следуют два важных вывода. Во-первых, приведенные данные показывают, что в принципе МХДЭ можно заменить нетоксичным и недорогим метилалем. Во-вторых, используя водный каталитический раствор, несмешивающийся с дихлорэтаном, мы впервые получили сферические гранулы сверхсшитого полимера, исходя из раствора линейного полистирола. 
Таблица 3. Сшивание линейного полистирола метилалем в присутствии раствора $\mathrm{ZnCl}_{2}$ и $\mathrm{FeCl}_{3}$ в соляной кислоте (концентрация полистирола в дихлорэтане $10 \%$, объемное соотношение органической и неорганической фаз 15:80 $\mathrm{cm}^{3}$ )

\begin{tabular}{|c|c|c|c|}
\hline \multirow{2}{*}{ Метилаль, моль } & Время, час & Набухание в толуоле, & $\mathrm{S}_{\text {Бэт, }}{ }^{2} / \Gamma$ \\
\hline 0.5 & 4 & 1.32 & 170 \\
\hline 0.5 & 7 & 1.25 & 190 \\
\hline 0.5 & 10 & 1.62 & 280 \\
\hline 0.5 & 15 & 1.58 & 450 \\
\hline 0.5 & 25 & 1.57 & 550 \\
\hline 1.0 & 10 & 1.05 & 1000 \\
\hline 1.5 & 10 & 1.60 & 850 \\
\hline
\end{tabular}

\section{Заключение}

Эксперименты показали, что среди безводных катализаторов ФриделяКрафтса самым удобным все-таки является хлорное олово. Этот катализатор достаточно активен, но не способствует участию дихлорэтана в формировании дополнительных сшивок полимера. К сожалению, этот катализатор дорог и его нельзя рекомендовать для промышленного синтеза сверхсшитых сорбентов. Использование водного кислого раствора хлоридов цинка и железа представляется более перспективным. Очень важно, что МХДЭ можно заменить метилалем и что сшитый материал на основе линейного полистирола можно получить сразу в ходе реакции в виде небольших сферических частиц. Это открывает возможность использовать не только промышленный линейный полистирол, но и превратить в полезные сорбенты пористый полистирольный упаковочный материал, в настоящее время в изобилии попадающий на свалки. Что касается низкой набухаемости сорбентов, то ее можно скорректировать, используя менее сшитые сополимеры или более разбавленный раствор линейного ПС.

Работа выполнена при финансовой поддержке РФФИ (грант 18-29-25007). Авторы также выражают благодарность к.х.н. М.М. Ильину за газохроматографический анализ монохлордиметилового эфира.

\section{Список литературы}

1. Davankov V.A., Tsyurupa M.P. Hypercrosslinked Polymeric Networks and Adsorbing Materials. Comprehensive Analytical Chemistry. Vol. 56, New York. Elsevier. 2011. 640 pp.

2. Chao Long, Qifen Li, Ying Li, Yuan Liu et al. // Chem. Eng. J. 2010. Vol. 160. pp. $723-$ 728. DOI: j.cej.2010.03.074

3. Dawson-Ekeland K.R., Stringfield R.T., Pat. USA 5,021,253, 1991.

4. Stringfield R.T., Goltz H.R., Norman S.I., Bharwada U.J. et al. Pat. USA 4,950,332, 1990.

\section{References}

1. Davankov V.A., Tsyurupa M.P. Hypercrosslinked Polymeric Networks and Adsorbing
5. Norman S.I., Stringfield R.T., Gopsill C.C., Pat. USA 4,965,083, 1990.

6. Pepper K.W., Paisley H.H., Young A. // J. Chem. Soc. 1953. pp. 4097-4105.

7. Справочник химика, М.-Л., Ленинградское отделение издательства Химия. 1964. Т. 2. $536 \mathrm{c}$.

8. Кислородсодержащие органические соединения. Часть 1. Справочноэнциклопедическое издание. СанктПетербург,. НПО Профессионал. 2007. 186 с. 
Materials, Comprehensive Analytical Chemistry, Vol. 56, New York, Elsevier, 2011, 640 pp.

2. Chao Long, Qifen Li, Ying Li, Yuan Liu et al., Chem. Eng. J., 2010, Vol. 160, pp. 723-728. DOI: j.cej.2010.03.074

3. Dawson-Ekeland K.R., Stringfield R.T., Pat. USA 5,021,253, 1991.

4. Stringfield R.T., Goltz H.R., Norman S.I., Bharwada U.J. et al., Pat. USA 4,950,332, 1990.

5. Norman S.I., Stringfield R.T., Gopsill C.C., Pat. USA 4,965,083, 1990.

Цюрупа Мария Петровна - д.х.н., Институт элементоорганических соединений им. А.Н. Несмеянова РАН, ведущий научный сотрудник, Москва, (499)-135-79-25

Даванков Вадим Александрович - професcop, д.Х.н., Институт элементоорганических соединений им. А.Н. Несмеянова РАН, Москва, (499) 135-64-71

\section{Блинникова Зинаида Константиновна} к.х.н., старший научный сотрудник, Иститут элементоорганических соединений им. А.Н. Несмеянова РАН, Москва, (499) 135-92-54

Давидович Юрий Александрович, старший научный сотрудник, Иститут элементоорганических соединений им. А.Н. Несмеянова РАН, Москва, (499) 135-65-13
6. Pepper K.W., Paisley H.H., Young A., J. Chem. Soc., 1953, pp. 4097-4105.

7. Spravochnik khimika (Chemist Handbook), Moskva-Leningrad, Khimiya, 1964, Vol. 2, 536 p.

8. Kislorodsoderzhaschie organicheskie soedineniya. Chast 1 (Oxygen-containing organic compounds. Part 1), Spravochnoentsiklopedicheskoe izdaniye, Sankt-Peterburg, Professional, 2007, 186 p.

Tsyurupa Maria Pe. - grand Ph.D., Nesmeyanov-Institute of Organoelement compounds RAS, leading scientific fellow, Moscow, E-maiil mts@ineos.ac.rur

Davankov Vadim A. - professor, grand Ph.D., Nesmeyanov-Institute of Organoelement compounds RAS, Head of Department, Moscow, Email davank@ineos.ac.ru

Blinnikova Zinaida Konstantinovna, Ph.D., senior scientific fellowб Nesmeyanov-Institute of Organoelement compounds RAS, Moscow, E-mail blinnikovazk@mail.ru

Davidovich Yurii Aleksandrovich, senior scientific fellow, Nesmeyanov-Institute of Organoelement compounds RAS, Moscow, E-mail 0839@rumbler.ru 